\title{
Child Disciplinary Practices in Relation to Household Head Education and Beliefs in Five Middle East and North African Countries: Cross Sectional Study-Further Analysis of Multiple Indicator Cluster Survey Data.
}

\author{
Abeer Hamdan, Manar Abdel-Rahman, PhD \\ Public Health Department, Qatar University
}

\section{Introduction}

Childhood period is considered the cornerstone of human life. In which the human builds the cognitive and socio-emotional domains of his life, in addition to the rapid physical growth (1). Parents consider this stage as the core for teaching children self-control, behavioral boundaries, and acceptable social behaviors. Child discipline is defined as any action taken by caregivers to teach children self-discipline and acceptable attitudes (2). Internationally, eight out of ten children are exposed to violent discipline by their caregivers (3). To reduce the prevalence of violent discipline against children, we should understand the social and economic factors that affect the choice of disciplinary methods. Despite the high prevalence of violent discipline in the Middle East and North African (MENA) region, only a few studies explored disciplinary methods in this region.

\section{Objectives}

To determine the prevalence of positive and violent disciplinary practices in five selected MENA countries and assess their association with household head education and beliefs of physical punishment.

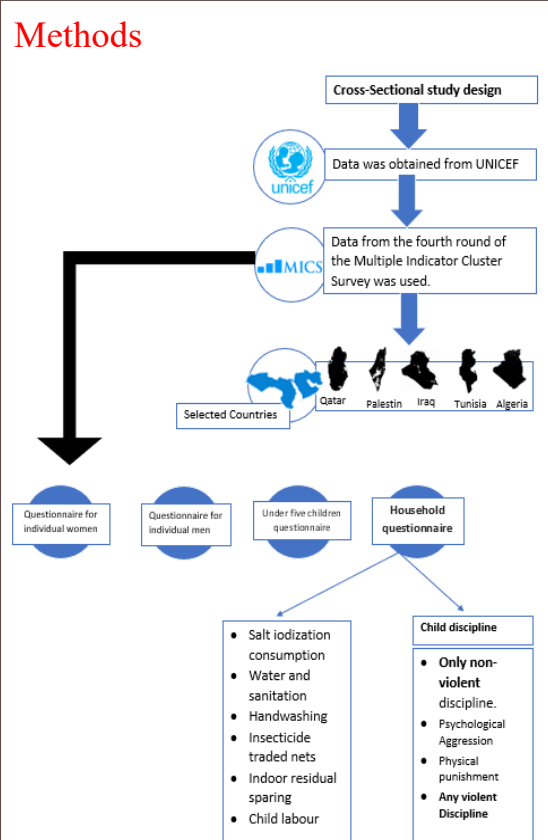

Figure1 :Study design and methods

A child was selected randomly from the household, and child discipline module was used to report disciplinary methods the child encountered during the last month period preceding the survey (4). Univariate and multivariable logistic regression were used to investigate the association between disciplinary practices with household head education and respondent's beliefs of physical punishment. The analysis was conducted using pooled data from all selected surveys and also for individual countries.

\section{Results \\ The overall prevalence of positive discipline was only $15 \%$ (95\% CI: 14.4-15.8), in the five countries, while the prevalence of violent discipline was $80 \%$ (95\% CI: 79.0 -80.5) (Figure 2). The prevalence of positive discipline was highest in Qatar $(40 \%$; 95\% CI: 35.0-44.4) and lowest in Tunisia (5\%; 95\% CI: 4.3-5.9) while the prevalence of violent discipline was highest in Tunisia (93\%; 95\% CI: 92.1-94.1), and lowest in Qatar (50\%; 95\% CI 44.7-55.0) (Figure 3). Overall, the household head education was not significantly associated with either positive or violent discipline after adjusting for covariates. However, respondents believe of disciplinary methods was significantly associated with both positive and violent discipline $(\mathrm{OR}=5.88 ; 95 \% \mathrm{CI}$ 4.97-6.96) and (OR=6.27; 95\% CI: 5.40-7.28), respectively. On country levels, the association between disciplinary methods and household head education was significant in Qatar, Palestine and Algeria only (figure $4 \& 6$ ). However, the association between disciplinary methods and beliefs of physical punishment was highly significant in all countries (Figure $5 \& 7$ ) $100 \%$
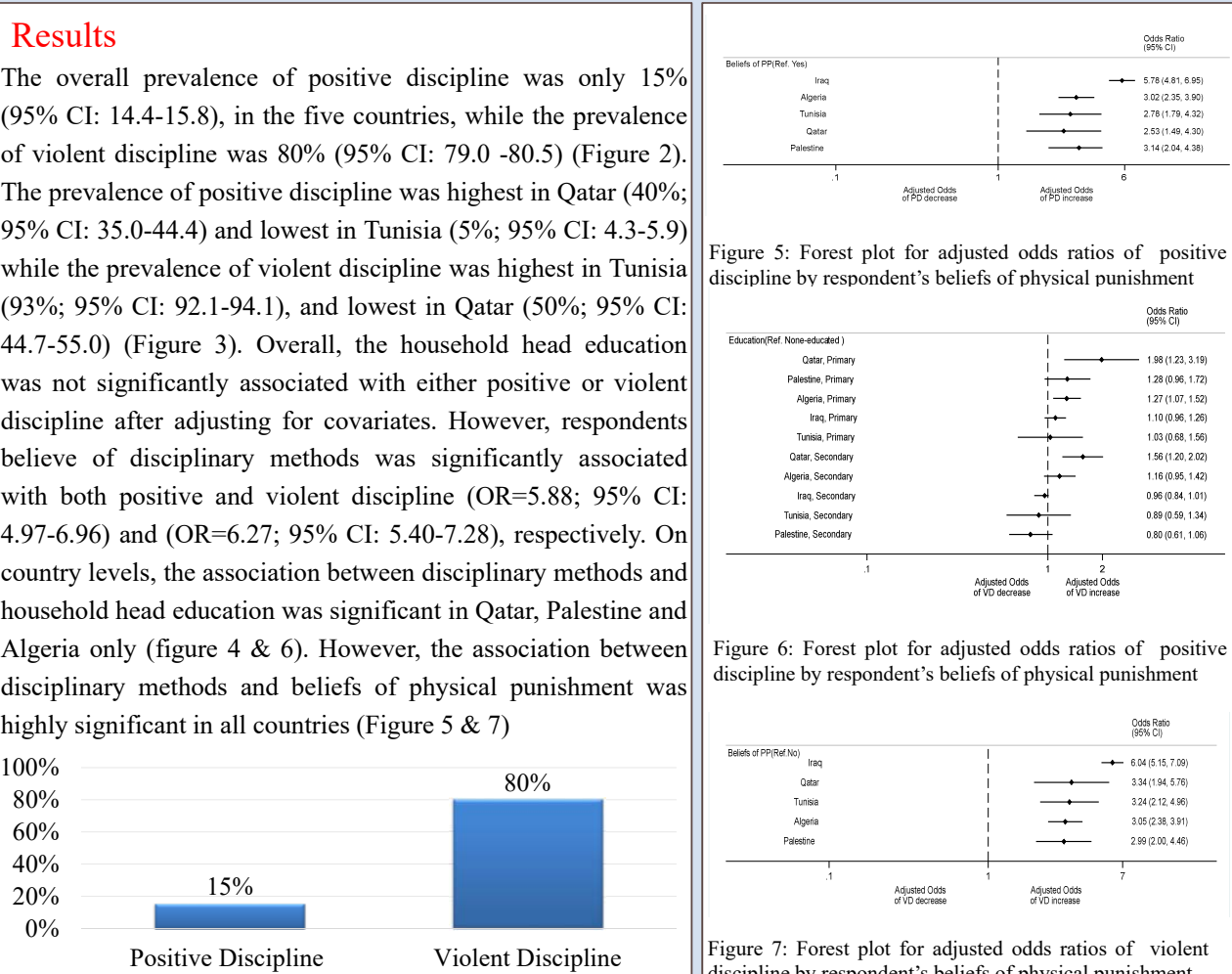 \\ Figure 5: Forest plot for adjusted odds ratios of positive discipline by respondent's beliefs of physical punishment

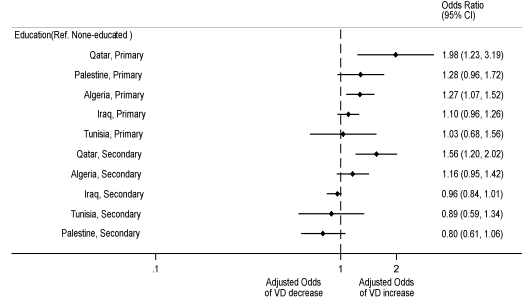 \\ Figure 6: Forest plot for adjusted odds ratios of positive discipline by respondent's beliefs of physical punishment

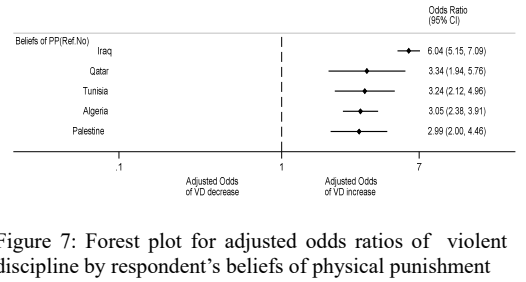

Figure 2: Prevalence of Disciplinary Practices in the overall Sample

$100.00 \%$

$90.00 \%$

$80.00 \%$

$70.00 \%$

$60.00 \%$

$50.00 \%$

$40.00 \%$

$30.00 \%$

$20.00 \%$

$10.00 \%$

$0.00 \%$

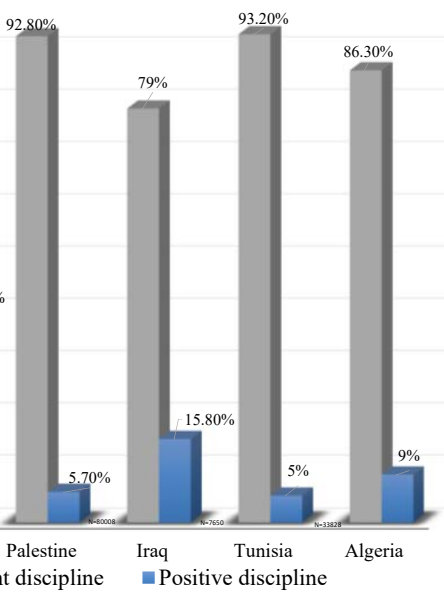

Figure 3: Prevalence of disciplinary practices by country

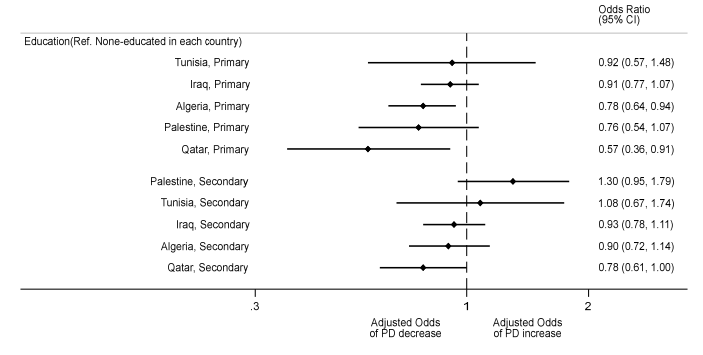

Figure 4: Forest plot for adjusted odds ratios of positive discipline by household head education

\section{Conclusion}

High rates of violent discipline in the MENA region might indicate an increase in mental, behavioral, and social problems and disorders in our future generation. Rapid action is needed to reduce the worsening of violent discipline, and it is consequences. There is a need for educational programs for caregivers to teach them alternative non-violent methods of discipline. Besides, these numbers should inform policymakers about the importance of the existence and the implementations of laws, policies, and regulations to protect children from all forms of violence to protect our future youths and ensure their health and wellbeing.

\section{References}

1. Bornstein MH, Britto PR, Nonoyama-Tarumi Y, Ota Y, Petrovic O, Putnick DL. Child development in developing countries: introduction and methods. Child Dev. 2012;83(1):16-31.

2. Unicef. Child Disciplinary Practices at Home Evidence from a Range of Low- and Middle-Income Countries. Report. Unicef: Unicef; 2010.

3. UNICEF. A Familiar Face: Violence in the lives of children and adolescents. New York; 2017.

4. Unicef. Surveys - UNICEF MICS 2019 [Available from: http://mics.unicef.org/surveys.

\section{Acknowledgment}

My special thanks is expressed to my supervisor, Dr. Manar, for her endless support and guidance and to all the Public Health faculty in Qatar University (QU). I would like to thank QU for offering the grant and for the opportunity to conduct this research and to UNICEF for providing the data. Special thanks for my great parents, my family and all my friends who supported me through this project especially Asma and Jenan.. 